\title{
Urban Planning and Natural Hazard Governance
}

Ricardo Marten Caceres, Camillo Boano, and Theresa Abrassart

Subject: Resilience, Vulnerability Online Publication Date: Nov 2019

DOI: $10.1093 /$ acrefore/9780199389407.013.347

\section{Summary and Keywords}

The establishment of effective linkages between institutional urban planning and disaster risk strategies remains a challenge for formal governance structures. For governments at all administrative scales, disaster resilience planning has required systemic capacities that rely on structures of governance, humanitarian frameworks, and budgetary capacities. However, with growing urbanization trends, humanitarian responses and Disaster Risk Management (DRM) frameworks have had to adapt their operations in contexts with high population density, complex infrastructure systems, informal dynamics, and a broader range of actors. Urban areas concentrate an array of different groups with the capability of contributing to urban responses and strategies to cope with disaster effects, including community groups, government agencies, international organizations and humanitarian practitioners. In addition, cities have running planning structures that support their administration and spatial organization, with instruments that supply constant information about population characteristics, infrastructure capacity and potential weaknesses. Processes and data ascribed to urban planning can provide vital knowledge to natural hazard governance frameworks, from technical resources to conceptual approaches towards spatial analysis. Authorities managing risk could improve their strategic objectives if they could access and integrate urban planning information. Furthermore, a collaborative hazard governance can provide equity to multiple urban actors that are usually left out of institutional DRM, including nongovernmental organizations, academia, and community groups. Traditional top-down models can operate in parallel with horizontal arrangements, giving voice to groups with limited access to political platforms but who are knowledgeable on urban space and social codes. Their still limited recognition is evidence that there is still a disconnect between the intentions of global frameworks for inclusive governance, and the co-production of an urban planning designed for inclusive resilience.

Keywords: urban planning, hazard governance, disaster planning, resilience, recovery, local actors, humanitarian response 


\section{Introduction}

The relationship between urban planning and the measures deployed after disaster events remains a complex political challenge. Governmental actions for planning and disaster governance at the urban scale can be "a highly contentious and difficult process, due to the multiple uncertainties that often characterize both scientific information and policy interests and constraints" (Florin \& Xu, 2014, p. 5). Government agendas have gradually incorporated structural frameworks with disaster risk reduction (DRR) and resilience strategies, in line with international initiatives such as the Hyogo Framework for Action (2005-2015), the Sendai Framework for DRR, and the 2030 Agenda for Sustainable Development (UNISDR, 2015). However, the translation of these objectives into effective planning and governance can be a contentious task; initiatives or plans are frequently misaligned, often due to institutional overlap, unclear regulatory frameworks, or endemic misadministration. These issues are further accentuated by the ways in which planning, disaster, and governance are defined and understood in urban contexts, which can sometimes reveal social, cultural, and political tensions that are difficult to overcome in management and legislation.

Migration and density trends, particularly in developing countries, show that urban environments will concentrate nearly two-thirds of the world's population (UN, 2018). This has clear implications in terms of political administration: first, cities should be thought of and designed in accordance with their growth, adjusting their infrastructure, accessibility, and economic opportunities; and second, local and national authorities should evaluate their response capacity in case of disaster events or recovery processes. Although these two challenges are interdependent, the frequent disconnect between urban planning authorities and the institutional framework designed around natural hazard governance can perpetuate ambiguity and inefficiency. The growing presence and influence of nongovernmental actors in urban issues, including private stakeholders, community organizations, and the humanitarian sector, has brought much-needed professional diversity, but also additional tensions, introducing alternative methodologies about intervention that can be at odds with each other. Consequently, a mismanaged natural hazard governance runs the risk of limiting or excluding vulnerable urban groups, and thus harms the mandate of ensuring adequate planning of future and overlapping risk.

This article will attempt to demonstrate the necessary links between urban planning and natural hazard governance, highlighting the opportunities that emerge when developing an integrated hazard response planning framework. In addition, it will argue that an adequate governance of risk must understand its planning as a toolkit in need of social imagination, that is, aware of socio-political dynamics, cultural sensibilities, and communities' relation with the environment. The first section will review existing literature on the discipline of urban planning in contexts of disaster and risk resilience, as well as provide an overview of the different definitions that exist regarding natural hazard governance. It will also introduce a critical appraisal of "the urban" and its purported definitions, in order to understand the sometimes-contradictory approaches towards city and disaster management. The second section will then make a case for an integrated framework of 
urban planning and governance in contexts of hazard risk: first, by identifying specific sources of planning tensions (spatial, temporal, conceptual) and contrasting them with examples of successful articulation through governance; and second, by suggesting an intersection of fields that could act as the basis for promoting the effectiveness and inclusiveness of urban strategies for risk resilience.

\section{Planning and the Anticipation of the Future}

The immediate disruption brought by disasters is a pivotal moment. Hazards test any given context's vulnerability and resilience, bringing to the fore the social, economic, and political capacity to engage in the different stages of recovery. Although institutions and civil society may have strategies and frameworks ready to deal with the impact of natural hazards, foresight and preparedness sometimes remain highly speculative technical practices. Disaster events trigger a complex, interconnected set of response instruments that are highly dependent on the adequate management of time and resources. This coping capability reflects the collective capacity of communities, organizations, and official institutions to withstand the full potential damage and destruction (Ahrens \& Rudolph, 2006; UN, 2002).

Planning for resilience requires systemic capacities that rely on structures of governance. In urban contexts, these frameworks are put at risk by particular tensions, such as population densities, infrastructure, systems of provision, land use management, and social interconnectedness. In contexts of disaster, these overlapping tensions are potential breaking points that may expose latent deficiencies in risk planning. If the effectiveness of planning lies at the core of successful governance, anticipating natural hazard impact through effective policy must be a priority for any integrated strategy. Putting in place such a framework, however, is a complex task that not only presupposes institutional capacity, but also relies on assumptions about what we mean by the urban, governance, and planning.

\section{The Governance of Risk}

Institutionality emerges from governmental order and the civil bodies that manage specific policies and practices. The contemporary nation-state, however, is not the only stakeholder defining strategic approaches, nor the sole administrator of the public sphere (Murray, 2017). Centralized government bodies have gradually decentralized, both in process and in space: power dynamics between actors and institutions can occur within and outside of the state, developing in a multi-centric, localized territorial arrangement (Rhodes, 1997). Urban areas, in particular, have shown the emergence of private actors, civil society, and international organizations as strategic partners who actively participate in decision-making processes and sometimes even bear responsibilities traditionally assumed by the state. 
The increasing participation of private actors in development and recovery processes has been flagged as an expansion of neoliberal tendencies (Gunewardena \& Schuller, 2008; Klein, 2007; Schuller \& Maldonado, 2016). Klein defines this as disaster capitalism, where disasters and catastrophic events become opportunities for orchestrated raids on the public sphere and blatant market opportunities (Klein, 2007). Areas debilitated by the impact of disaster are fertile ground for implementing neoliberal policies during times of severe crisis because they demand quick responses and emergency aid. In the aftermath of disaster, cash-strapped local governments start relying on the goodwill and generosity of donors, creating a path for neoliberal policies. These policies, as Schuller and Maldonado argue, are facilitated by shifts in donor flows, advancing the interests of private constituencies and creating windows of opportunity provided by disaster (Schuller \& Maldonado, 2016).

The dispersion of institutional responsibilities has consolidated through the complex transformation of governments under capitalist market forces, a neoliberalization of both human and non-human processes (Castree, 2008), and a "hollowing-out" of institutional capacities and the state itself (Rhodes, 1994). Indeed, private actors are increasingly pivotal in directing urban development schemes and influencing essential planning processes. At a global scale, infrastructure, land management, and urban economic distribution have been deregulated, privatized, or commoditized, fragmenting the traditional uniformity of the systems of provision (Bevir \& Trentman, 2007). This renegotiated interface (Murray, 2017) creates an inevitable tension among actors, while posing a challenge for governance: responsibility and decision-making can be compromised according to partial interests that are often not designed to address the needs of the most vulnerable.

On the other hand, grassroots organizations and civil society initiatives are increasingly recognized in the transformation of cities and city-making. Although their impact is usually at a smaller scale, area-based approaches that are capable of benefitting a wider range of vulnerable groups facing similar circumstances are required in urban settings

(Grünewald, 2012; Gupta, 2015; IRC, 2015). However, more needs to be known about how these approaches can be supported cost-effectively and in partnership with municipal authorities, the private sector (including local service providers), and different bodies within the civil society, and about how they can be integrated into broader urban planning strategies at the city-wide scale (Gupta, 2015).

Recent literature has examined this shift as a new form of governance (Walker, Whittle, Medd, \& Watson, 2010), where authority has been forced to act beyond traditional legislative tools (laws and regulations), adapting to include informal means of agreement, negotiated spaces, and bottom-up strategic approaches (Rosenau, 2004). Once decision-making processes are not exclusive to the state, horizontal and vertical dialogue become instrumental, where governance is redefined as a set of "complex public and/or private coordinating, steering, and regulatory processes established and conducted for social (or collective) purposes where powers are distributed amongst multiple agents, according to formal and informal rules" (Burns \& Stohr, 2011). 
Under a framework of risk, governance is equally subject to a growing intersection of interests, capacities, and power. As multiplicity becomes part of urban social dynamics, accountability and initiative become crucial components that, if unplanned for, can hinder the capacity for recovery after a shocking event. The management of risk and its corresponding governance is, as Renn (2008, p. 9) defines it, "the rules, conventions, processes and mechanisms concerned with how relevant risk information is collected, analysed and communicated, and how management decisions are taken" (Renn, 2008, p. 9). With growing urbanization, the variety of these relations grows in complexity and tension, but also in richness and ingenuity.

As suggested by Allen et al. (2017), a useful concept is that of "risk traps" (p. 477) to "help to explain how risk accumulation cycles are produced and reproduced over time and where ... to capture how particularly marginalized low-income urban dwellers find themselves in situations of increased exposure and vulnerability to environmental hazards, paradoxically despite and even because of investments undertaken to improve their precarious living conditions." Emerging from an action-oriented research project in the periphery of Lima, for the authors, "creating conditions that are necessary to move out of risk traps requires engaging with different actors' capacity to act-of which investment capacities form one part-in the realms of social inclusion policies, urban development and environmental sustainability" (Allen et al., 2017, p. 479).

Urban areas concentrate an array of different actors with the capability of contributing to urban responses and strategies to cope with disaster effects. Among these are: local, regional, and national government agencies and line departments (including the police and military); the private sector (including the insurance sector, banks and lenders, smallscale service providers, professional service providers); local civil society organizations (including Nongovernmental Organisations, Community-Based Organisations, and FaithBased Organisations); affected communities; academic and research institutions (including various epistemic communities); and international humanitarian actors (including International NGOs and United Nations agencies as well as UN country teams). It is increasingly recognized that responding to urban crises requires the involvement of all these actors (Ramalingam \& Knox-Clarke, 2012; Zetter \& Deikun, 2011) and that effective responses must consider the particular circumstances of the poorest and most vulnerable groups, including the community organizations that support them (IFRC, 2010; Schilderman, 2010).

\section{Natural Hazard Governance}

The collective efforts to implement response in the event of natural hazards follow, in principle, this multidimensional aperture. Addressing and managing the effects of natural hazards has become a negotiated process between governments and international organizations, between the public and private sector, between official and informal practices. In consequence, strategies for resilience and recovery can vary in terms of financial capacity, territorial control, legal enforcement, time management, and even language.

Page 5 of 24

PRINTED FROM the OXFORD RESEARCH ENCYCLOPEDIA, NATURAL HAZARD SCIENCE (oxfordre.com/naturalhazardscience). (c) Oxford University Press USA, 2019. All Rights Reserved. Personal use only; commercial use is strictly prohibited (for details see Privacy Policy and Legal Notice). 
Despite the emergence of actors external to governmental bodies, the core of natural hazard governance is still anchored in the state's capacity to plan, manage, and control the impact of disasters on a national and supranational scale (Boin, Rhinard, \& Ekengren, 2014; Roberts, 2013). This implies that risk, as defined and understood, depends on laws and regulatory bodies, and can be the responsibility of a particular ministry or authority depending on said definition. Depending on state approaches, the responsibility of natural hazard governance can fall under different frameworks, including but not limited to: an agency within the Department of Homeland Security apparatus in the United States (Roberts, 2019); an emerging multi-stakeholder consortium of governmental and international actors in Nepal (Oven, 2019); or a rather rigid top-down system going through a complex process of decentralization in China (Sim \& Lei Yu, 2018).

Categories for response often respond to partisan or civic interests, socially constructed platforms, and natural conditions: "Disasters are political events, mediated by news broadcasts and bottom-up social media phenomena . . . bound to security and environmental threats" (Roberts, 2019). Communication about disasters, whether through media or official channels, has long been acknowledged as central to the management of potential disaster crises (Rattien, 1990), raising awareness for future events (Rodriguez, 1997) and potentially functioning as a didactic channel of information for preparedness (Bradley, McFarland, \& Clarke, 2014). Governments can influence and control the amount and depth of information being circulated during a disaster response or fall short of monitoring false or misleading information. Social media, in particular, can rapidly spread dubious, unchecked details, which could serve a political purpose beyond the event itself (Alexander, 2013).

The centrality of government-based disaster strategies is anchored in agencies or bodies created to manage their implementation. Their efficiency, however, is determined by their capacity of operation, budget control, integration with other government branches, and scale of mandate. Efficient risk and hazard governance depend on autonomy and coordination, but also on the political and legal reach that the corresponding institutions have to conceive, develop, and enact their policies. In the absence of a structured governance framework, disaster risk management can turn to a bureaucratic overlap where responsibilities are not clearly established. Hazard response can easily turn into a reactionary process that falls to government bodies with more logistical capacity but with less than ideal expertise and training specifically related to disaster.

Although every context has its own power dynamics and degree of decentralization, stakeholders in disaster responses are increasingly diverse. Urban areas, for example, have complex institutional landscapes and social and spatial structures that international humanitarian agencies must understand and engage with (Pavanello, 2012). Humanitarian agencies will need to consult, coordinate with, and seek permission from many more actors-such as national and local governments, urban development authorities, informal "gatekeepers," militias and gangs, among many others-than they will in rural areas (Pavanello, 2012). The inverse is also true, as local authorities have to deal with the plethora of humanitarian actors. In this context, establishing partnerships and interagency coordi- 
nation is an unavoidable necessity (Crisp, Morris, \& Refstie, 2012; IASC, 2010; Kyazze, Baizan, \& Carpenter, 2012; Pavanello, 2012; Ramalingam \& Knox-Clarke, 2012).

Prevention and response capacities of local governments, particularly in low- and middleincome countries, may be further eroded when their staff are affected by disasters or conflict or when they have been implicated in urban violence (Zetter \& Deikun, 2011). Vital administrative resources, including land registers, maps, office equipment, or municipal buildings, may have been damaged or destroyed, creating significant difficulties for local administrators and their counterparts, and for international humanitarian actors, in planning and implementing emergency assistance (Ramalingam \& Knox-Clarke, 2012; Zetter \& Deikun, 2011). The IASC (2010) also notes how the rapid influx of internally displaced persons (IDPs) and refugees into urban areas can create additional difficulties for urban administrations and governance structures, which may not have been able to provide basic services to the pre-crisis population.

These local governments may be overwhelmed and thus may not always be able or willing to provide basic services or to support the provision of humanitarian assistance to the urban poor and displaced (Feinstein International Center, 2012; Haysom, 2013; Refstie, Dolan, \& Okello, 2010; Sanyal, 2012; Tibaijuka, 2010; Zetter \& Deikun, 2011). In other cases, national and local governments have developed institutional structures and procedures to deal with the constant pressures of protracted crises affecting urban areas. However, the capacities of local authorities and the level of inter-institutional coordination can vary considerably between towns and cities, as can the demographic pressures of displacement (Vidal, Atehortúa, \& Salcedo, 2013).

\section{Urban Planning in the Context of Risk}

The importance of planning in natural hazard governance has been gradually acknowledged, both as a central component in risk reduction (Burton, Kates, \& White, 1993) and as a wider political activity that is concerned with policy-making and multi-sectoral bargaining (Sylves, 2014). However, the definition and scope of planning is often misconstrued, particularly when framed against disaster risk management policies and countryspecific approaches. For the purpose of this article, we will briefly review some definitions of planning that have been interconnected with natural hazard governance and understand their link with the urban dimension.

Emergency or disaster planning follows the need for preparedness against vulnerabilities and risk, relying on procedures, protocols, or plans for prevention and response (Alexander, 2002). Alexander (2014) further argues that emergency planning operates as a scenario-based strategy designed for crises, involving "a nested hierarchy of processes that are permanent (i.e., ongoing), and temporary in the strategic, tactical and operational spheres" (p. 129). This perspective positions emergency plans as technical extensions of disaster management, but less so as part of city planning strategies (Britton \& Lindsay, 1995), even if "urban planning and land-use decisions can help to shape the overall exposure of the city and urban activities to particular hazards" (Dodman et al., 2013). Emer- 


\section{Urban Planning and Natural Hazard Governance}

gency planning depends on spatio-temporal conditions that could potentially be supported by the physical considerations inherent to urban and regional planning, yet these linkages are seldom incorporated (Alexander, 2014).

Humanitarian planning is a combination of the strategies for preparedness and response as carried out by the humanitarian aid sector (Dodman et al., 2013). Although planning is sometimes loosely attached to a rather broad set of actions, the concept is usually assigned to the Humanitarian Response Plans (HRP) required by the United Nations cluster model (OCHA, 2011). OCHA defines HRPs as strategic response planning templates, which emerge from a two-step process where a country's strategies for disaster are followed by cluster plans with specific points for intervention and objectives according to each cluster's responsibility or mandate (OCHA, 2009). Despite the humanitarian sector's active role in disaster management and hazard governance, it has been slow to adapt to urban contexts (Boano \& Marten, 2018; Dodman et al., 2013; Maynard, Parker, YosephPaulus, \& Garcia, 2018). The gradual urbanization of risk has proven challenging, with a dissonance between technical frameworks for intervention (such as the cluster model) and the tumultuous dynamics of urban environments.

As Maynard et al. (2018) point out, national-scale urban planning is usually disconnected from community-level authorities, which are strained out of capacity during disasters and have limited resources for an adequate governance model: "There is also limited guidance available-either for urban planners working in humanitarian contexts or for humanitarian agencies trying to provide them with support" (p. 266). Humanitarian models of disaster planning, whether led by government strategies or directed by international organizations, were traditionally understood as post-disaster activities. However, current emergency relief operations tend to run in parallel to conflictive recovery processes that often continue after planned interventions are meant to be completed.

Humanitarian activities, therefore, face an epistemological challenge and a need to adapt their operative framework as urban risks increase in frequency and impact. This has been acknowledged by humanitarian organizations, which have been forced to reframe their strategic approach and develop a new set of definitions about the urban dimension (ICRC, 2015; MSF, 2016), as well as other authors who have encouraged a deeper intersection between humanitarian practices and urban systems (Campbell, 2016; Da Silva, 2016). There have been additional efforts aimed at designing adequate plans for urban intervention: an increased level of engagement with urban authorities and a renewed spatial perspective (Landau, Wanjiku-Kihato, Misago, Obot, \& Edwards, 2016); a renewed understanding of scale, strategic planning, and institutional adaptation (BRC, 2016); or the systematic incorporation of risk management into urban planning (OCHA, 2009). Brown, Boano, Johnson, Vivekananda, and Walker (2015) argue that these shifts in humanitarianism have a direct influence on aspects of governance, particularly those concerned with local coordination and partnerships, local government capacity, and local power and authority structures. However, the gaps between planning concepts widen when seen through the lens of governmental actions. 
The sectoral awareness from humanitarian agencies is not as palpable in traditional hazard governance. Institutionalized urban planning operates mostly as an independent practice from the risk and policy-making sphere and intersections with disaster risk planning are circumstantial rather than holistic. Both urban planning and natural hazard governance are anchored on spatial parameters, territorial administration, and temporal management, yet these dimensions are rarely planned and designed in tandem. Institutionally, risk management agencies or bodies measure and define objectives in the case of shocking events, whereas urban planning remains a discipline shaped by the constancy and micro-variance of the city. And although this difference in perspective is somewhat expected and necessary, a systemic lack of communication can lead to a debilitated structure of governance, supporting the view that "institutional failure resulting in bad governance can be regarded as the root cause of both disasters and underdevelopment" (Ahrens \& Rudolph, 2006).

\section{Disaster Governance and the Challenge of Ur- ban Diversity}

With increasing urbanization, the question arises: whose responsibility is it to plan against hazard risk in cities? Although not without difficulties, there have been important efforts to place disaster risk management as integral to global development, with international agendas supporting frameworks aligned with the objectives of the Sustainable Development Goals (SDGs). These include the Hyogo Framework for Action (2005-2015), the Sendai Framework for DRR, and the 2030 Agenda for Sustainable Development (UNISDR, 2007). SDG 11 in particular is concerned with promoting political capacities for disaster risk management, suggesting a 2020 target to "increase the number of cities and human settlements adopting and implementing integrated policies and plans towards inclusion, resource efficiency, mitigation and adaptation to climate change, resilience to disasters, and develop and implement . . . holistic disaster risk management at all levels" (UN, 2018).

These initiatives have pushed agendas about climate change and disaster risk management into governmental sector development planning and programs (Wamsler, 2007). Low- and middle-income countries with high urban density and numerous informal settlements are particularly vulnerable to hazards; in many cases, the integration of actual policies or institutional capacity for a hazard governance framework is incipient at best and their linkages to urban planning are usually absent. For example, Malawi, frequently affected by extreme flooding and droughts, implemented its National Disaster Risk Management Policy until 2015 (Government of Malawi, 2015), with its strategies managed by a department of Risk Management Affairs. Despite the policy's acknowledgement of a need for holistic development planning, the natural hazard governance structure is strictly confined to disaster-oriented technical committees, and there is no direct coordination with urban planning authorities. Costa Rica's National Policy for Risk Management outlines its efforts to strengthen the national risk governance, establishing long-term institu- 
tional planning for natural hazards such as earthquakes, flooding, and hurricanes (Government of Costa Rica, 2015). However, most strategies for preparedness and recovery are assigned to bodies within the National Emergency Commission, with no consolidated support from national ministries or local authorities responsible for urban planning or development.

As these and several other cases show, natural hazard governance models in many countries are hampered by both an overreliance on top-down agencies responsible for risk management, and a disconnect between said agencies and other planning authorities, including local authorities. Although national governments have stronger mandates and budgets, lower levels of government have much clearer knowledge of local contexts and participatory processes (Brown et al., 2015; Murray, 2017; Roberts, 2019). In addition, many of these frameworks, even if institutionally sound, have limited capacity to engage with nontraditional stakeholders, particularly those who operate at local scales and are not restricted to official frameworks. "The concept of governance includes actors outside of textbook definitions of government. Nonprofit and voluntary organizations, quasi-governmental organizations, and business play a more important role in recovery than the literature has so far accounted for" (Roberts, 2019).

\section{Urban Planning for Disasters}

In the context of disaster, the atomization of responsibilities of different active agents can pose a challenge of organization and management. Top-down frameworks may prove to be too broad; national strategies or disaster response mechanisms can come at odds with structural or territorial planning models that focus on large-scale priorities but miss the nuances of locality. Natural hazard governance, often conceived as entirely comprehensive, is also highly idiosyncratic. Even if the scale and magnitude of a disaster event is regional or national, response and recovery are contingent on local context, including in concentrated, highly populated areas. In urban settings these variances increase due to the multiplicity of actors, built environment, financial capabilities, accessibility, and the multidimensional manifestations of informality—conditional, legal, practical (Marx \& Kelling, 2019).

Urban planning has evolved into a multidisciplinary field, driven by a modernist conception of society where events can be managed and planned for, with multiple ways of knowing aligning for positive change (Sandercock, 1998). Traditional regulatory tools assigned to urban planning, such as land use zoning, masterplans, and natural resources coordination, can also be understood as an extension of state control. As Yiftachel (1998) explains, elite interests are embedded in national states; slanted social dynamics can be instrumentalized through planning, sanctioning into space measures of control and disciplinary power. The instruments themselves are highly procedural in nature (Hall \& Tewdwr-Jones, 2011) and require a set of learning and expertise that may discard non-official actors and fail to include different, alternative planning knowledges (Rydin, 2007). 
A comprehensive integration between urban planning and disaster risk frameworks is yet to be established, as are clear principles to guide the process (March \& Leon, 2013). However, existing commonalities between the planning sphere and disaster risk suggest how coordinated actions could be enhanced and developed. Several authors identify these opportunities in the technical capacities that urban planning can provide on hazard prevention, for example: restricting growth in risk-prone areas and enforcing legally binding building regulations (Fleischhauer, Greiving, \& Wanczura, 2005); including design and engineering professionals in disaster risk strategies (Chmutina, Bosher, Coaffee, \& Rowlands, 2014); developing hazard risk maps, GIS capabilities, and Spatial Data Infrastructures (Sutanta, Rajanifard, \& Bishop, 2010); and including information databases containing indicators about socioeconomic and geophysical characteristics, development trends, and availability of human and material resources (March \& Leon, 2013).

Indeed, strategic urban planning is permanently producing data and design systems that are essential for emergencies. Authorities managing risk could improve their strategic objectives if they could access and integrate these knowledge caches. However, this perspective can limit the disciplinary knowledge exchange as a purely technocratic exercise. National disaster risk agencies or ministries could be cornered as such through governance frameworks, by being established as specialist units with very specific mandates and institutional limitations. Urban planning, while wider in scope and diversity of actors, can also be misconstrued as a productive dimension in charge of managing city spaces through technological means and clear-cut policy objectives. Although expertise and distinctiveness are essential, vulnerability in cities is not exclusive to one single specialist sector. Moreover, as suggested by Allen et al. (2017), it is important to acknowledge that "without a long-term perspective on how urban risk traps operate, state responses are likely to continue focusing on large-scale disasters, missing the invisible and slow violence of risk traps that affect a sizeable percentage of impoverished women and men" ( $p$. 497).

Even when co-production of knowledge is stimulated, and multi-stakeholder participation is encouraged, urban planning and disaster risk management can find themselves in conflict. A study comparing collaborative processes between urban planning and DRR activities in Israel and the United Kingdom (Chmutina et al., 2014) explains some of these problems: lack of consensus on stakeholder roles and degrees of responsibility; missing information about DRR objectives and general sense of awareness about hazard impact; and, perhaps more importantly, that despite the existence of legislation and institutional frameworks, many stakeholders had no practical experience in DRR, while risk specialists had limited understanding of planning principles.

In societies where this institutional clarity is not available (due to political context, financial capability, or institutional weakness), these professional and technical dissonances are augmented. Furthermore, an idealized scenario where a state's natural hazard governance functions in harmony with other planning fields is still a top-down approach that perpetuates the notion that cities are a by-product of official authorities. Urban areas are complex regions with many social disparities, and rarely are all citizens granted the same 
opportunities for development and protection. "Whilst urban planning systems can do much to help in disaster recovery they can also do much to hinder it, especially if they are rigid or inflexible, or if changes are made without full cognizance being taken of the ramifications for those affected" (Minnery, 2018, p. 528). In such a complex scenario it is therefore fundamental that "community-based data and knowledge production can allow policymakers to better capture the experiences, perceptions and capacities to act of those at risk. They can therefore contribute to improving the design and targeting of state investment programs and the evaluation of the impacts they have on every day and smallscale risks" (Allen et al., 2017, p. 498).

\section{Towards a Progressive, and Urban, Natural Hazard Governance}

A reliable governance is the intentional shaping of the flow of events to realize desired public needs (Parker \& Braithwaite, 2003). Although its effectiveness is initiated by state involvement, several authors have pointed out that environmental pressures and climate change demand flexible governance models-open to broader actor participation and more diverse power dynamics, including in contexts of disaster (Brunner et al., 2005; Dietz, Ostrom, \& Stern, 2003; Djalante, 2012; Djalante, Holley, \& Thomalla, 2011). This framework has been denominated as Adaptive Governance, which puts environmental resilience at the fore and is concerned with a horizontal dialogue between institutional, social, and international actors (Holley, 2010). Djalante (2012) argues that adaptive governance models can succeed if they are supported by multi-stakeholder platforms that have decision-making capacity, knowledge recognition, and established networks.

Adaptive governance's concern with environmental risks facilitates its extension into disaster risk management. In essence, an inclusive, trans-institutional version of adaptive governance that acknowledges disaster vulnerabilities, and understands multiple institutional and organizational capacities, can shape a solid natural hazard governance. These principles are somewhat implicit or alluded to in global humanitarian charters (UNISDR, 2007) and international multilateral organizations (GFDRR, 2015). Despite these calls for inclusiveness, natural hazard governance models are still very much driven by strong authorities. The management of risk, due in part to its social sensitivity and response demands, are part and parcel of state control and government practices, and influential participatory channels are hard to find.

Furthermore, aside from humanitarian stakeholders (which usually hold a considerable degree of power or influence), it is rare to encounter civil society groups with enough leverage to become determinant in shaping natural hazard governance. In urban contexts, the diversity and uniqueness of these groups add to the challenge of incorporating their perspectives, even if their knowledge is exceptional. This is critical when specific community risks might elude national natural hazard strategies or could be better addressed by nongovernmental actors, such as community organizations, city committees, and the private sector (Brown et al., 2015). As in urban areas, vulnerabilities and risks are heterogeneous and determined by different factors such as gender, socioeconomic dependency ratio, level of income, location, and history of the settlement; all these aspects 


\section{Urban Planning and Natural Hazard Governance}

affect the different formations of risks, implying that planning investments need to be place-based (Allen et al., 2017).

Creating an inclusive process of hazard governance requires critical awareness and power dynamics with sufficient foresight to understand the advantages of multi-stakeholder frameworks. However, as Pelling (2011) explains, the first step is to recognize that there should be a hazard governance in the first place, where urban vulnerability and disaster risk are seen as part of a general governance, rather than being sector specific. Allen et al. (2017) thus argue for a co-production of governance, where partnerships between government and citizens create "more just and resilient urban environments" (p. 173), conceptualized across three main points: building an institutional environment that allows bottom-up initiatives for resilience and justice within their framework; focusing on longitudinal strategic planning to prevent the bulk of resources being spent on short-term initiatives; and integrating participation and local knowledge as more than procedural requisites, and instead introducing them as part of governance's own pulse.

Thus, a co-produced natural hazard governance would be an institutional consortium that manages hazards horizontally, engaging with disaster risk knowledge at different scales and with different actors, including those that traditionally might be marginalized. At the same time, this would require the governmental disposition to allow dissenting voices, and the institutional maturity to grapple with disagreement proactively, rather than blocking it, for example, in order to channel the efficient delivery of post-disaster aid. This framework of inclusiveness can also extend to urban planning, which can become a shared field, not only of institutional co-production, but of nontraditional actors who participate daily in the ways in which cities take form and develop. As Allen et al. (2017, p. 499) observe, this expanded field should be flexible enough "to evaluate the actual impacts of risk-increasing interventions, such as roads that promote the occupation of hazardous areas, as well as the impacts of not investing in improvements that can reduce people's vulnerability to everyday risks."

As March, Kornakova, and Handmer (2017) argue, urban planning can be a key mechanism for disaster risk governance. It provides tools that can demonstrably improve natural hazard mitigation strategies, including:

- The creation of vulnerability maps based on aggregated data, showing density, topography, administrative boundaries, and systems of provision across city limits;

- The establishment of land use criteria to orient urban growth and restrict growth and development in areas prone to higher hazard risk;

- The consolidation of regulatory frameworks such as building codes and legally binding instruments that guarantee long-term practices of safety in the built environment.

The success of these strategies is measurable in the capacity to integrate them into effective policy, which usually implies long-winded political negotiations and a willingness to adapt frameworks to varying political, economic, social, and environmental interests. In this context, urban planning might increase the viability of successful natural hazard gov- 
ernance, because its instruments and mechanisms are somewhat vetted as part of regional and national planning structures. As Hopkins (2001) points out, urban planning is understood as part of local governments' decision-making criteria, and expects to have its output become policy and regulation. DRR bodies may lack this influence, particularly if understood as reactionary models designed for exceptional circumstances (the hazard) rather than the continuous management of urban resilience.

A truly progressive natural hazard governance, however, should go further than promoting cross-governmental capacities. As with governance practices, urban planning is also a variegated field, extending beyond ministerial expertise. The obvious relation is between governments and international organizations or humanitarian actors, which usually operate with their own mandates and are guided by principles that fall into fixed definitions of recovery (Brun, 2016). This extends to urban environments, where humanitarian agencies can become de facto suppliers of infrastructure and overseers of territorial arrangements (March et al., 2017). Urban planning designed for contexts of risk can be an articulator between dissimilar stakeholders that, nonetheless, aspire to achieve comparable results.

Although political complexity and power dynamics can easily derail this approach, it is still valid to push for governance models interlinked with urban planning regimes. They can provide much needed DRR support to local governments (highlighted by the Sendai Framework as indispensable actors) who understand city needs and have immediate access to resources (Panda \& Amaratunga, 2019). Similarly, NGOs with urban knowledge and established data collection models can strengthen community safety in partnership with institutions, other organizations, and individuals. A collaborative hazard governance provides equity to multiple urban actors which, in the case of NGOs for example, may have unmatched access and flexibility for DRR, "such as intervening vulnerability reduction for different vulnerable and marginalized groups" (Lassa, 2018).

Finally, the less obvious relation, or the most invisible, is probably the most in need of encouragement: grassroots, social participation. A progressive intersection between urban planning and natural hazard governance would be able to incorporate community groups and provide agency to organizations with different, but valuable, territorial knowledge. Granting community groups public participation in planning and governance can sharpen local assessments of vulnerabilities and risks, help to conceive appropriate response strategies, and increase community resilience, "as active citizens play a key role in building disaster resilient communities” (Sarzynski \& Cavaliere, 2018).

Frameworks of co-production can only strengthen the reach of natural hazard governance. When nurtured by the different layers of knowledge inherent in urban planning, the instruments for DRR multiply in technical capacity, technological assets, spatial management, and scalar impact. Despite potential political limitations and power hierarchies, governments could gradually acknowledge that local actors are constant planners: making and unmaking the city through formal and informal arrangements; building makeshift physical strategies for resilience; maximizing resources in contexts of extreme deficiency; 
mapping needs with spatial ingenuity; and constantly cognizant of time frames and the latency of disaster.

The dynamic nature of urban planning potentially allows it to address and reflect on changes in community composition, goals, needs, and so forth over time. The inclusive and collaborative basis of democratically based urban planning allows for the development of new knowledge and its further translation to various professionals, decision makers, agencies, and the community.

(March \& Kornakova, 2017, p. 245)

\section{Conclusion: An Urban Retrofitting of Hazard Governance}

An overview of literature related to DRR planning and management shows that the field has had an important evolution, particularly since the introduction of clearer guidelines for humanitarian interventions (particularly through the UN cluster system) and the global push for international frameworks for disaster resilience, such as the SDGs and the Hyogo and Sendai frameworks. This shift has produced considerable knowledge about the impact of hazards in all aspects of national development, clearly ascribing a political value to strategizing for disaster through coordination and multi-actor processes. In broad terms, there seems to be an agreement that traditional top-down models should operate in parallel with horizontal arrangements (Allen et al., 2017; Renn, 2008; Tierney, 2012). Actors outside national governments can be part of DRR programs, including civil society, the private sector, and humanitarian bodies of different scale, providing cross-cutting, strategic knowledge to the established institutional disaster governance frameworks.

The inclusion of nontraditional actors in the planning process has a direct effect on governance: it produces a model where institutional rigidity gives way to a looser but more flexible environment for collective management, where common interests, such as hazard mitigation, are integrated towards effective policy-making. Disaster resilience, when understood as a cross-institutional, longitudinal process, allows for a more inclusive understanding of vulnerability and risk, particularly in the often chaotic diversity of urban environments.

Despite this consensus, the driving principles of integrated models of governance (and natural hazard governance in particular) remain a complex challenge. In some cases, states may not be willing to cede control of emergency interventions, due to interests and biases, but also due to a short-sighted understanding of disasters, framing the actions in the case of shock events as reactionary measures devoid of holistic, trans-institutional planning. DRR and natural hazard governance are still perceived as specialist fields, with 


\section{Urban Planning and Natural Hazard Governance}

independent technical skills and an assumed complexity that may discourage relevant actors from participating in their conception.

Furthermore, urban planning, which is a central component of national and regional development, is rarely integrated into DRR frameworks, less so to governance models. In the best of cases, urban planning is understood as a neutral provider of territorial instruments, a technical field developing strategies to monitor and assess populations, and the arbiter of efficient spatial order. However, urban planning can easily become a political tool for segregation, augmenting the vulnerability of urban populations that can be left unrecognized or forced into entrenched informality.

The indispensable integration between urban planning and natural hazard governance may not be clear at first, but several commonalities are notable. From a technical standpoint, urban planning instruments and data resources could support and inform DRR, not only in isolated exceptional circumstances, but also as part of a permanent collaboration that would necessarily enrich the framework of natural hazard governance. In addition, urban planning's embeddedness in programmatic national planning could advance DRR strategies as part of broad master plans and urban strategies for growth, understanding risk as a constant-not an accumulation of anomalies. This is particularly pressing in southern experiences, where the frequency of risks poses a major challenge for sustained resilience, highlighting the need to "consider synergies in dealing with disaster risk reduction, climate change, and vulnerability to everyday risks and small-scale episodic disasters when conceptualizing and implementing processes for alternative development. The convergence of extensive risks associated with low-severity and high-frequency events and intensive risks associated with major hazards contributes to the reproduction of risk accumulation cycles" (Allen et al., 2017, p. 500).

However, to achieve full consistency with the principles and objectives of, for example, the Sendai Framework, the intersection between urban planning and natural hazard governance should be more than a trans-institutional engagement. It should support the progressive participation of non-state actors who are usually kept invisible, and who have knowledge about space, urban dynamics, and social codes. Clearly this includes the humanitarian sector, as well as specialized NGOs, local authorities, and the private sector; all of these actors, through mandates or by other circumstances, engage with planning and governance activities themselves. Their inclusion in larger frameworks would provide an even broader knowledge base about urban conducts, spatial practices, and alternative urban planning initiatives.

Finally, the greatest challenge remains how to develop broader public engagement that includes community groups, particularly those with limited access to political platforms. Traditionally, these groups might be disregarded even if they possess alternative means of spatial knowledge and governance. Their limited recognition is evidence that there is still a disconnect between the intentions of global frameworks for inclusive governance, and the true spaces for the co-production of urban planning. This requires a retrofitting of urban planning as a field and governance as state-driven. When disasters strike, sur- 
vival becomes imperative; if those who hold power and shape territory acknowledge diversity, the collective strategies for resilience might become more inclusive, less reactionary, and planned for an uncertain future.

\section{Further Reading}

Béné, C., Mehta, L., McGranahan, G., Cannon, T., Gupte, J., \& Tanner, T. (2018). Resilience as a policy narrative: Potentials and limits in the context of urban planning. Climate and Development, 10(2), 116-133.

Cretney, R. M. (2017). Towards a critical geography of disaster recovery politics: Perspectives on crisis and hope. Geography Compass, 11(1), 1-11.

Fiddian-Qasmiyeh, E. (2015). South-south educational migration, humanitarianism and development: Views from Cuba, North Africa and the Middle East. Oxford, U.K.: Routledge.

Gaillard, J. C. (2019). Disaster studies inside out. Disasters, 43(S1), S7-S17.

Kelman, I. (2012). Disaster diplomacy: How disasters affect peace and conflict. London, U.K.: Routledge.

Lavell, A., \& Maskrey, A. (2014). The future of disaster risk management. Environmental Hazards, 13(4), 267-280.

Lizarralde, G., Johnson, C., \& Davidson, C. (Eds.). (2010). Rebuilding after disasters. London, U.K.: Routledge.

Maynard, V., Parker, E., Yoseph-Paulus, R., \& Garcia, D. (2018). Urban planning following humanitarian crises: Supporting urban communities and local governments to take the lead. Environment and Urbanization, 30(1), 265-282.

\section{References}

Ahrens, J., \& Rudolph, P. M. (2006). The importance of governance in risk reduction and disaster management. Journal of Contingencies and Crisis Management, 14, 207220.

Alexander, D. (2002). From civil defence to civil protection-and back again. Disaster Prevention and Management: An International Journal, 11(3), 209-213.

Alexander, D. (2013). Social media in disaster risk reduction and crisis management. Springer Science + Business Media, 20, 717-733.

Alexander, D. (2014). Emergency and disaster planning. In A. Lopez Carresi, M. Fordham, B. Wisner, I. Kelman, \& J. C. Gaillard (Eds.), Disaster Management. London, U.K.: Routledge. 
Allen, A., Griffin, L., \& Johnson, C. (2017). Environmental justice and urban resilience in the global south. London, U.K.: Palgrave Macmillan.

Allen, A., Zilbert Soto, L., Wesely, J., Belkow, T., Ferro, V., Lambert, R., . . . , Samanamú, S., (2017). From state agencies to ordinary citizens: Reframing risk-mitigation investments and their impact to disrupt urban risk traps in Lima, Peru. Environment and Urbanization, 29(2), 477-502.

Bevir, M., \& Trentmann, F. (2007). Introduction: Consumption and citizenship in the new governance. In M. Bevir \& F. Trentmann (Eds.), Governance, consumers and citizens: Consumption and public life. London, U.K.: Palgrave Macmillan.

Bradley, D. T., McFarland, M., \& Clarke, M. (2014). The effectiveness of disaster risk communication: A systematic review of intervention studies. PLOS Currents Disasters, August 22, Edition 1.

BRC. (2016). Annual Review 2016. London, U.K.: British Red Cross.

Brown, D., Boano, C., Johnson, C., Vivekananda, J., \& Walker, J. (2015). Urban crises and humanitarian response: Literature review. London, U.K.: UCL.

Boano, C., \& Marten, R. (2018). Think urban and learn from the city: Exploring urban dimensions of humanitarianism. London, U.K.: Urban Crisis Learning Partnership, UCL.

Boin, A., Rhinard, M., \& Ekengren, M. (2014). Managing transboundary crises. Journal of Contingencies \& Crisis Management, 22, 131-142.

Britton, N. R., \& Lindsay, J. (1995). Integrating city planning and emergency preparedness: Some of the reasons why. International Journal of Mass Emergency and Disasters, 13(1), 93-106.

Brun, C. (2016). There is no future in humanitarianism: Emergency, temporality and protracted displacement. History and Anthropology, 27(4), 393-410.

Brunner, R., Steelman, T., Coe-Juell, L., Cromley, C., Edwards, C., \& Tucker, D. (2005). Adaptive Governance: Integrating Science, Policy, and Decision Making. New York, NY: Columbia University Press.

Burns, T. R., \& Stohr, C. (2011). The architecture and transformation of governance systems: Power, knowledge and conflict. Human Systems Management, 30, 173-195.

Burton, I., Kates, R. W., \& White, G. F. (1993). The environment as hazard (2nd ed.). New York, NY: Guilford Press.

Campbell, L. (2016). Stepping back: Understanding cites and their systems. ALNAP Working Paper. London, U.K.: ALNAP/ODI.

Castree, N. (2008). Neoliberalising nature: Processes, effects, and evaluations. Environment and Planning A: Economy and Space, 40(1), 153-173.

Page 18 of 24

PRINTED FROM the OXFORD RESEARCH ENCYCLOPEDIA, NATURAL HAZARD SCIENCE (oxfordre.com/naturalhazardscience). (c) Oxford University Press USA, 2019. All Rights Reserved. Personal use only; commercial use is strictly prohibited (for details see Privacy Policy and Legal Notice). 
Chmutina, K., Bosher, L., Coaffee, J., \& Rowlands, R. (2014). Towards integrated security and resilience framework: A tool for decision-makers. Procedia Economics and Finance, $18,25-32$.

Crisp, J., Morris, T., \& Refstie, H. (2012). Displacement in urban areas: New challenges, new partnerships. Disasters, 36(S1), 23-42.

Da Silva, J. (2016). City resilience index: Understanding and measuring city resilience. London, U.K.: Arup.

Dietz, T., Ostrom, E., \& Stern, P. C. (2003). The struggle to govern the commons. Science, 302(5652), 1907-1912.

Djalante, R. (2012). Adaptive governance and resilience: The role of multi-stakeholder platforms in disaster risk reduction. Natural Hazards and Earth System Sciences, 12(9), 2923-2942.

Djalante, R., Holley, C., \& Thomalla, F. (2011). Adaptive governance and managing resilience to natural hazards. Disaster Risk Science, 2, 1-14.

Dodman, D., Brown, D., Francis, K., Hardoy, J., Johnson, C., \& Sattwewaite, D. (2013). Understanding the nature and scale of urban risk in low- and middle-income countries and its implication for humanitarian preparedness, planning and response. London, U.K.: IIED.

Feinstein International Center. (2012). Refugee livelihoods in urban areas: Identifying program opportunities; Recommendations for programming and advocacy. Boston, MA: Friedman School of Nutrition Science and Policy, Tufts University.

Fleischhauer, M., Greiving, S., \& Wanczura, S. (2005). Management of natural hazards in Europe: The role of spatial planning in selected EU member states. Journal of Environmental Planning and Management, 49(5), 739-757.

Florin, M. V., \& Xu, J. (2014). Risk governance: An overview of drivers and success factors. UNISDR and IRGC.

Folke, C., Hahn, T., Olsson, P., \& Norberg, J. (2015). Adaptive governance of social-ecological systems. Annual Review of Environment and Resources, 3(1), 441-473.

GFDRR. (2015). Annual report 2015. Washington, DC: World Bank Group.

Government of Costa Rica. (2015). Política Nacional de Gestión del Riesgo 20162030.

Government of Malawi. (2015). National disaster risk management policy.

Grünewald, F. (2012). Aid in a city at war: The case of Mogadishu, Somalia. Disasters, 36, 105-125. 
Gupta, H. (2015). Home sweet home: Housing practices and tools that support durable solutions for urban IDPs. Geneva, Switzerland: MIT, DRAN, and IDMC.

Gunewardena, N., \& Schuller, M. (2008). Capitalizing on Catastrophe: Neoliberal Strategies in Disaster Reconstruction. Lanham, MD: AltaMira.

Hall, P., \& Tewdwr-Jones, M. (2011). Urban and regional planning. London, U.K.: Routledge.

Haysom, S. (2013). Sanctuary in the city? Reframing responses to protracted urban displacement. HPG Report 33, June. London, U.K.: ODI.

Holley, C. (2010). Facilitating monitoring, subverting self-interest and limiting discretion: Learning from "new" forms of accountability in practice. Columbia Journal of Environmental Law, 36, 127-211.

Hopkins, L. D. (2001). Urban development: The logic of making plans. Washington, DC: Island Press.

IASC. (2010). IASC strategy: Meeting humanitarian challenges in urban areas. Geneva, Switzerland: IASC.

ICRC. (2015). Urban services during protracted armed conflict: A call for a better approach to assisting affected people. Geneva, Switzerland: International Committee of the Red Cross.

IFRC. (2010). World disasters report 2010: Focus on urban risk. Geneva, Switzerland: IFRC.

IRC. (2015). Humanitarian action in a new urban world. World Humanitarian Summit: Regional Consultation, Europe and Others, IRC, February 3-4.

Klein, N. (2007). The shock doctrine: The rise of disaster capitalism. New York, NY: Metropolitan Books.

Kyazze, A. B., Baizan, P., \& Carpenter, S. (2012). Learning from the city: British Red Cross urban learning project scoping study. London, U.K.: BRC.

Landau, L., Wanjiku-Kihato, C., Misago, J. P., Obot, D., \& Edwards, B. (2016). Becoming urban humanitarians engaging local government to protect displaced people. Washington, DC: The Urban Institute.

Lassa, J. (2018). Roles of non-government organizations in disaster risk reduction. Oxford research encyclopedia of natural hazard science.

March, A., Kornakova, M., \& Handmer, J. (2017). Urban planning and recovery governance. In A. March \& M. Kornakova (Eds.), Urban planning for disaster recovery. Oxford, U.K.: Elsevier. 
March, A., \& Kornakova, M. (2017). Planning for recovery: Ideas and problematics. In A. March \& M. Kornakova (Eds.), Urban planning for disaster recovery. Oxford, U.K.: Elsevier.

March, A., \& Leon, S. (2013). Urban planning for disaster risk reduction: Establishing 2nd wave criteria. Conference Proceedings, SOAC 2013.

Marx, C., \& Kelling, E. (2019). Knowing urban informalities. Urban Studies, 56(3), 494-509.

Maynard, V., Parker, E., Yoseph-Paulus, R., \& Garcia, D. (2018). Urban planning following humanitarian crises: Supporting urban communities and local governments to take the lead. Environment and Urbanization, 30(1), 265-282.

Minnery, J. (2018). Urban planning for disaster recovery. Urban Policy and Research, 36(4), 527-529.

Murray, N. (2017). Urban disaster risk governance: A systematic review. London, U.K.: EPPI-Centre UCL.

MSF. (2016). Where is everyone? Responding to emergencies in the most difficult places.

OCHA. (2009). Annual report 2009. Geneva, Switzerland: OCHA.

OCHA. (2011). OCHA and slow-onset emergencies. Geneva, Switzerland: OCHA.

Oven, K. (2019). Natural hazards governance in Nepal. Oxford research encyclopedia of natural hazard science.

Panda, A., \& Amaratunga, D. (2019). Resilient cities. Oxford Research Encyclopedia of Natural Hazard Science.

Parker, C., \& Braithwaite, J. (2003). Regulation. In P. Cane \& M. Tushnet (Eds.), The Oxford Handbook of Legal Studies (pp. 119-145). Oxford, U.K.: Oxford University Press.

Pavanello, S. (2012). Rethinking the humanitarian response: Emerging approaches for engagement in urban crises. Cambridge, MA: ATHA.

Pelling, M. (2011). Adaptation to climate change: From resilience to transformation. London, U.K.: Routledge.

Ramalingam, B., \& Knox Clarke, P. (2012). Meeting the urban challenge: Adapting humanitarian efforts to an urban world. London, U.K.: ALNAP.

Rattien, S. (1990). The role of the media in hazard mitigation and disaster management. Disasters, 14, 36-45. 
Refstie, H., Dolan, C., \& Okello, M. C. (2010). Urban IDPs in Uganda: Victims of institutional convenience. Forced Migration Review, 34, 32-33.

Renn, O. (2008). Risk governance: Coping with uncertainty in a complex world. London, U.K.: Earthscan.

Rhodes, R. A. (1994). The hollowing out of the state: The changing nature of the public service in Britain. Political Quarterly, 65, 138-151.

Rhodes, R. A. (1997). Understanding governance policy networks, governance and accountability. London, U.K.: Open University Press.

Roberts, P. (2013). Disasters and the American state: How politicians, bureaucrats, and the public prepare for the unexpected. Cambridge, U.K.: Cambridge University Press.

Roberts, P. (2019). Natural hazards governance in democratic states with developed economies. Oxford Research Encyclopedia of Natural Hazard Science.

Rodriguez, D. M. (1997). Dominating time in the operational decision making process. Newport, RI: United States Naval War College.

Rosenau, J. (2004). Strong demand, huge supply: Governance in an emerging epoch. In I. Bache \& M. Flinders (Eds.), Multi-level governance. Oxford, U.K.: Oxford University Press.

Rydin, Y. (2007). Re-examining the role of knowledge within planning theory. Planning Theory, 6(1), 52-68.

Sandercock, L. (1998). Towards cosmopolis: Planning for multicultural cities. London, U.K.: John Wiley.

Sanyal, R. (2012). Refugees and the city: An urban discussion. Geography Compass, 6(11), 633-644.

Sarzynski, A., \& Cavaliere, P. (2018). Public participation in planning for community management of natural hazards. Oxford Research Encyclopedia of Natural Hazard Science.

Schilderman, T. (2010). Putting people at the centre of reconstruction. In M. Lyons, T. Schilderman, \& C. Boano (Eds.), Building back better: Delivering people-centred housing reconstruction at scale. Rugby, U.K.: Practical Action.

Schuller, M., \& Maldonado, J. (2016). Disaster capitalism. Annals of Anthropological Practice, 40(1), 61-72.

Sim, T., \& Yu, J. (2018). Natural hazards governance in China. Oxford Research Encyclopedia of Natural Hazard Science. 
Sutanta, H., Rajanifard, A., \& Bishop, I. D. (2010). Integrating spatial planning and disaster risk reduction at the local level in the context of spatially enabled government. Proceedings of the GSDI 12 World Conference: Realising Spatially Enabled Societies, Singapore.

Sylves, R. (2014). Disaster policy and politics: Emergency management and homeland security. Washington, DC: CQ Press.

Tibaijuka, A. (2010). Adapting to urban displacement. Forced Migration Review, 2(34), 4.

Tierney, K. (2012). Disaster governance: Social, political, and economic dimensions. Annual Review of Environment and Resources, 37(1), 341-363.

UN. (2002). Living with risk: A global review of disaster reduction initiatives 2002. Geneva, Switzerland: United Nations.

UN. (2014). Sustainable Development Goals: Goal 11. Make cities and human settlements inclusive, safe, resilient and sustainable.

UN. (2018). 2018 revision of world urbanization prospects.

UNISDR. (2007). Guidelines: National platform for disaster risk reduction. Geneva, Switzerland: United Nations.

UNISDR. (2015). UNISDR Annual Report 2015.

Vidal, R., Atehortúa, C., \& Salcedo, J. (2013). Local government responses to internal displacement in urban areas: A study of Bogotá and Cali, Colombia. Washington, DC: Brookings-LSE Project on Internal Displacement.

Walker, G., Whittle, R., Medd, W., \& Watson, N. (2010). Risk governance and natural hazards: CapHaz-Net WP2 report. Lancaster, U.K.: Lancaster Environment Centre, Lancaster University.

Wamsler, C. (2007). Bridging the gaps: Stakeholder-based strategies for risk reduction and financing for the urban poor. Environment and Urbanization, 19(1), 115-142.

Yiftachel, O. (1998). Planning and social control: Exploring the dark side. Journal of Planning Literature, 12(4), 395-406.

Zetter, R., \& Deikun, G. (2011). A new strategy for meeting humanitarian challenges in urban areas. Forced Migration Review, 38, 48-50.

Ricardo Marten Caceres

University College London, The Bartlett Development Planning Unit

Camillo Boano

Page 23 of 24

PRINTED FROM the OXFORD RESEARCH ENCYCLOPEDIA, NATURAL HAZARD SCIENCE (oxfordre.com/naturalhazardscience). (c) Oxford University Press USA, 2019. All Rights Reserved. Personal use only; commercial use is strictly prohibited (for details see Privacy Policy and Legal Notice). 


\section{Urban Planning and Natural Hazard Governance}

University College London, The Bartlett Development Planning Unit

\section{Theresa Abrassart}

World Bank 